Educational Psychology, 1961, 52, 30-34.

UNDERWOOD, B. J. Experimental psychology: An introduction. New York: Appleton-Century-Crofts, 1949.

UNDERWOOD, B. J. Speed of learning and amount retained: $A$ consideration of methodology. Psychological Bulletin, 1954, 51, 276-282.

UNDERWOOD, B. J. Forgetting. Scientific American, 1964, 210,91-99.

\title{
Reminiscence in recognition memory for faces
}

GRAEME WALLACE, MAX COLTHEART, ${ }^{1}$ and KENNETH $I$. FORSTER, Monash University, Clayton, Victoria, Australia

Milner (1968) demonstrated the occurrence of reminiscence in recognition memory for photographs of faces. The existence of this effect was confirmed, and the effects of inspection time and of varying the inspection-test delay were studied. The results were considered in the context of the work of Kleinsmith \& Kaplan (1963) on arousal and memory.

Underwood (1953, p. 47) noted that reminiscence could virtually be described as a "prewar" phenomenon and this state of affairs has prevailed until quite recently. However, a resurgence of interest in this phenomenon has recently occurred (Hochberg \& Galper, 1967; Scheirer \& Voss, 1969). One aspect of the problem has been dealt with by Milner (1968), who demonstrated a reminiscence effect in recognition memory for faces. In this experiment, Ss viewed an inspection series of 12 photographs of faces for $45 \mathrm{sec}$ and were then presented with a test series of 25 such photographs and instructed to indicate which 12 of these they had seen in the inspection series. Recognition accuracy was significantly greater when there was a 90-sec delay between inspection and test than when there was no delay.

The aim of the experiments reported here was to explore this effect by varying both the inspection time and the delay between inspection and test. METHOD

The Ss were 200 trainee teachers enrolled at a Teachers' College. They were all unpaid volunteers and were tested in groups of four. Each $S$ viewed an inspection series of 12 faces and then a test series of 25 faces, and he was told to choose the 12 he had previously seen. The 25 photographs were full-face, head-and-shoulder photographs of students from another teaching institution. They were $2 \times 2 \frac{1}{4}$ in. and were mounted in a 5 by 5 array on a sheet of cardboard; the test series was similarly mounted in a 4 by 3 array. The test series combined photographs of 12 men and 13 women; the inspection series contained photographs of 6 men and 6 women.

Half the Ss viewed the inspection series for $45 \mathrm{sec}$; half viewed it for $15 \mathrm{sec}$. Within each of these two groups, five different inspection-test delays were used: $0,45,90$, 180 , and $360 \mathrm{sec}$. Thus, there were 10 groups, each of 20 Ss.

\section{RESULTS}

The mean number of faces correctly recognized (out of 12) is plotted in Fig. 1 as a function of delay interval for each inspection period. The means and variances of each group are given in Table 1.

Analysis of variance revealed a significant effect of delay time. $[F(4,190)=3.20, p<.02$. The functions relating mean number recognized to delay period were highly similar for the two inspection periods, with a rise from 0 to $45 \mathrm{sec}$, a decline, and then a slight increase to $360 \mathrm{sec}$. Mann-Whitney U tests showed that recognition was significantly better at $45 \mathrm{sec}$ delay than at $0 \mathrm{sec}$ delay for the 45 -sec inspection group $(p<.05)$. For the 15 -sec inspection group, this effect did not reach significance, because it was obscured by a ceiling effect. That is, a considerable number of Ss achieved the maximum score (12) at each delay condition.

The same experiment was conducted

Table 1

Mean Scores for Groups of 20 Ss at Various Delays and Presentation Rates Delay Between Inspection and Retest (in Sec)

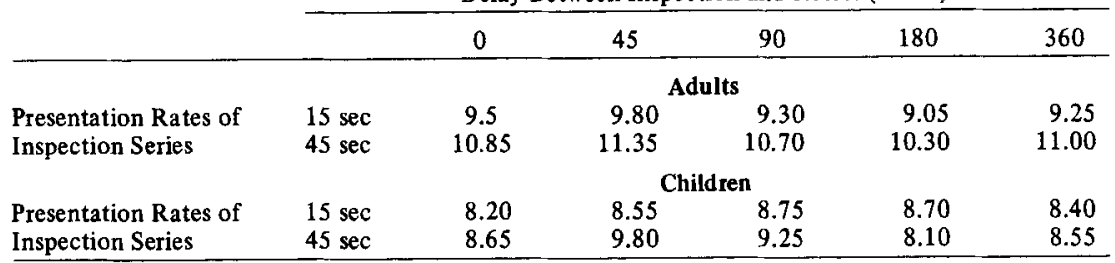
performance reflects the adequacy of using 200 children, aged 10 to 12 years, as Ss. The results are given in Fig. 2. Neither the effects of delay $[F(4,190)=2.20$, $p>.05]$ nor the effects of inspection period $[F(1,190)=2.27, p>.05]$ reached significance. However, for both inspection periods, performance was better at $45 \mathrm{sec}$ delay than at $0 \mathrm{sec}$ delay. The function relating recognition accuracy to delay with 45-sec inspection period was very similar to the two adult functions shown in Fig. 1. The 15-sec function exhibited some differences, possibly because this period was too short for the children to cope with.

\section{DISCUSSION}

Although a ceiling effect presented difficulties in data analysis, clear evidence for a reminiscence effect in recognition memory for faces was obtained. This effect occurred at a 45-sec inspection-test delay rather than at the $90-\mathrm{sec}$ delay as found by Milner (1968).

The demonstration of reminiscence effect for recognition memory raises problems for the view that recall and recognition are fundamentally different processes. Kintsch (1968) has suggested that retrieval is involved in recall but not in recognition. Hence, organization of the stimulus material, which is thought to affect retrieval, exerts no effect on recognition. By implication, recognition initial storage more directly than does recall. But to account for reminiscence effects, it would have to be assumed that the actual storage of the information improves in some way during the delay interval. Alternatively, it can be assumed that retrieval is also involved in recognition (Mandler et al, 1969), and that it is the efficiency of the retrieval mechanism that is affected by the delay.

A speculative answer to the question concerning the cause of this effect is provided by the work of Kleinsmith \& Kaplan (1963), who found that material that produced high arousal was less well recalled than low-arousal material, with immediate recall. However, the material was better recalled than was low-arousal material when a delay was introduced between presentation and recall. McLean 


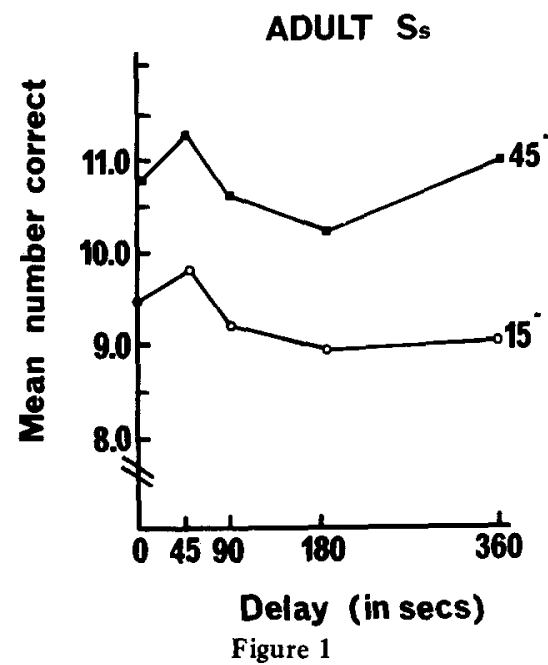

(1969) has obtained similar results. Kleinsmith and Kaplan proposed an explanation of their effect in terms of consolidation; high arousal is considered to lead to improved consolidation while, at the same time, immediate recall is impaired by a strongly activated consolidation process.
Since it seems likely that photographs of human faces may reasonably be classified as arousing, it is conceivable that in terms of Kleinsmith and Kaplan's views, a marked reminiscence effect would occur with these stimuli. However, this explanation rests on a demonstration of the arousal properties of human faces.

\section{REFERENCES}

HOCHBERG, J., \& GALPER, R. E. Recognition of faces: An exploratory study. Psychonomic Science, 1967, 9, 619-620.

KINTSCH, W. Recognition and free recall of organized lists. Journal of Experimental Psychology, 1968, 78, 481-487.

KLEINSMITH, L. J., \& KAPLAN, S. Paired-associate learning as a function of arousal and interpolated interval. Journal of Experimental Psychology, 1963,65, 190-193.

MANDLER, G., PEARLSTONE, Z., \& KOOPMANS, $H$. Effects of organization and semantic similarity on recall and recognition. Journal of Verbal Learning \& Verbal Behavior $1968,8,410-423$.

MILNER, B. Visual recognition and recall after right temporal lobe excision in man. Neuropsychologia, 1968, 6, 191-209.

McLEAN, P. D. Induced arousal and time of recall as determinants of paired-associate recall. British Journal of Psychology, 1969, 1, 57-62.

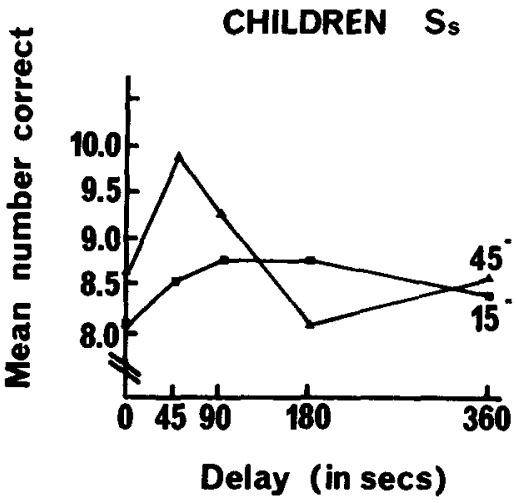

Figure 2

SCHEIRER, C. J., \& VOSS, J. F. Reminiscence in short-term memory. Journal of Experimental Psychology, 1969, 80, 262-270. UNDERWOOD, B. J. Learning. In P. Farnsworth, Q. McNemar, and O. McNemar (Eds.), Annual Review of Psychology. Vol. 4. 1953. Pp. 31-58.

NOTE

1. Now at University of Waterloo, Waterloo, Ont., Canada. 